\title{
Parental Mediation of the Use of the Internet: A Psychometric Study with Portuguese Pre-adolescents
}

\author{
Ângela Sá Azevedo ${ }^{10000-0003-1108-4011]}$ Íris M. Oliveira ${ }^{10000-0003-4262-6768]}$ and Paulo C. \\ Dias ${ }^{1[0000-0001-6876-3723] ~}$ \\ ${ }^{1}$ Universidade Católica Portuguesa, Faculty of Philosophy and Social Sciences, Centre for \\ Philosophical and Humanistic Studies, Portugal \\ amazevedo@ucp.pt imoliveira@ucp.pt pcdias@ucp.pt
}

\begin{abstract}
Individuals start using technological resources, among which the Internet, increasingly earlier in life. Parents are currently challenged to mediate the use of technologies by their sons/daughters, while simultaneously fostering their autonomy and self-regulation. Parental mediation of offspring's use of the Internet is needed, given its acknowledged risks. This study intends to offer preliminary psychometric evidence on the adaptation and validation of the Parental Mediation Scale (PMS) with Portuguese pre-adolescents. A total of 355 pre-adolescents $(55.2 \%$ female) aged 10 to 13 years old $(M=11.20, D P=.93)$ from northern Portugal participated in this study. The PMS was translated from Castilian to Portuguese by two experts in the field and in both languages. Participants completed a sociodemographic questionnaire and the Portuguese PMS version on paper, in group and at the classroom setting. Results from confirmatory factor analyses suggested that a revised bi-dimensional measurement model yielded an adequate fit to the sample. Cronbach's alpha of .82 were found for the active/participated mediation and the restrictive mediation PMS subscales. Variations in parental mediation for participants' sex, and statistically significant relations with participants' age, use of the Internet, and parents' educational levels were found. Future studies might recruit broader samples in terms of age, school levels and geographic areas to add evidence on the psychometric properties of the Portuguese PMS version. Nonetheless, this study might stimulate empirical and practical attention to parental mediation of sons/daughters' use of the Internet.
\end{abstract}

Keywords: Use of the Internet, Parental Mediation, Measurement.

\section{Introduction}

Since its emergence in the 80's, the use of technological devices and the Internet has exponentially increased. According to data provided by the Eurostat [1], in 2019, 88\% of the European Union families used the Internet, which represented an increase of 33\% compared to 2009. Likewise, the access to the Internet increased from 64\% in 2009 to $90 \%$ in 2019 . Taking the particular case of Portugal into account, $75 \%$ of individuals aged 16 to 74 years old used the Internet in 2019, with $77 \%$ reporting its daily use.

The proliferation of the Internet is understandable, as it serves various purposes, such as social connectedness, rapid search for information, globalized and remote work, 
and, in some cases, an escape to a complex social reality [2]. However, the need for adult mediation in the use of the Internet by children, pre-adolescents and adolescents has been highlighted over the years [3, 4]. Adult mediation is needed especially when individuals seem to start using technological resources increasingly earlier in their lives [5]. Internet addiction, social isolation, and cyberbullying are among the risks of an unsupervised use of the Internet [6]. These risks raise concerns to parents, who often struggle deciding how to mediate the use of technologies by their sons/daughters. To sustain additional research and practice on parental mediation of offspring's use of the Internet, this study aims at providing preliminary psychometric evidence on the adaptation and validation of the PMS with Portuguese pre-adolescents.

\subsection{Pre-adolescents' use of the Internet}

Data from the EU Kids Online [7] suggest that Portuguese individuals start using the Internet as early as 10 years old. The literature has already shown that children and adolescents tend to daily use the Internet, which increase their vulnerability to online risks and raises concerns toward educational, familiar and social consequences $[6,8]$.

Variations in the use of the Internet in the childhood and adolescence periods of the lifespan have been found. From five to eight years old, children seem to increase their active use of the Internet, as they enjoy online educational games or games triggering competition $[9,10]$. Additionally, while females seem to use the Internet mostly to access social networks, males seem to use it to access games and entertainment sources [10]. Sill, differences for sex in the use of the Internet seem to dissipate with age [11]. On the other hand, social connectedness becomes a more salient aspect of individuals' lives during adolescence. This is illustrated by behaviors toward group integration exhibited in the school, sport, leisure and other contexts. However, research has alerted for the risks prompted by the digital era in teens' social connectedness, particularly considering their affectivity and interactions with peer groups [12]. Although pre-adolescents and adolescents seem to use the Internet to explore and approach the community, they seem also to do it in a more superficial fashion due to social withdrawal and sometimes misuse of the Internet. Research has even demonstrated that the continuous use of the Internet might increase the likelihood of experiencing affective difficulties, which can ultimately result in relational problems later on in adulthood [12].

Children and adolescents have been shown to frequently misuse technology in terms of the length of exposition to digital devices and the access to age-inappropriate contents. Youths face a high probability of exposing themselves to online risks, such as cyberbullying, pornography, violence, or sexting $[6,13,14]$. One in 10 children (9-10 years old) and pre-adolescents (10-12 years old), particularly girls, reports he/she has already been a victim of cyberbullying. Approximately $5 \%$ of Portuguese children and adolescents have already been sent sexual messages, or sexting, which is still below the European average (11\%). About $11 \%$ of pre-adolescents and adolescents referred having dated someone met online, which is still below the European average (26\%). In Portugal, dating someone who was met online seems to be more frequent from 12 years old onward. Moreover, $27 \%$ of Portuguese children and adolescents confirmed they have already accessed sexual-related images, with a higher frequency for 15-16 years old adolescents and for children from low social-economic backgrounds [5]. Based on 
the Net Children, Go Mobile study [15], about $10 \%$ of children and adolescents referred they have already felt uncomfortable with something they visualized online. Girls, particularly aged 13 to 14 years old, and individuals from low social-economic backgrounds were the most represented ones within such a percentage.

\subsection{Parental mediation of sons/daughters' use of the Internet}

To prevent the risks associated with the use of the Internet, the literature has called for the promotion of digital competencies among youths $[16,17]$ and for the adult mediation of pupils' use of the Internet [18, 19]. Parental mediation has been highlighted as a central protective factor against children's and pre-adolescents' risk behaviors and hazards of using the Internet [20, 21, 22].

Increased attention has been devoted to parental mediation of sons/daughters' use of the Internet, as children and pre-adolescents seem to more frequently use the Internet at the family setting $[20,21,22]$. Although pre-adolescents and adolescents might hold competencies to use technologies, they still need parental supervision, modelling and support to adequately and healthily make use of the digital resources [23]. Research has suggested that parents are usually concerned about how to sustain their sons/daughters' autonomy while simultaneously supervising their use of the Internet [19]. Moreover, parental modelling the use of the Internet and offspring's perceived permission to do it have been shown to minimize teens' digital risk behaviors [24].

Parental mediation can be defined as any activity or strategy implemented by parents or legal caregivers to protect their offspring from the risks of using the Internet and other technological assets [25]. The literature has identified three main styles of parental mediation: restrictive mediation, active mediation, and co-using [26]. Restrictive mediation is featured by parents' control of the length of their sons/daughters' use of the Internet and of the personal information they disclosure online. It is also characterized by parents' establishment of rules for their sons/daughters to use the Internet and digital applications. In this style, sons/daughters are not directly involved in the decision-making processes regarding the use of the Internet and are expected to obey the rules established by their parents [27]. Active mediation is characterized by parents' discussion of aspects related to the use of the Internet with their sons/daughters and by parents' physical presence when their offspring are using the Internet. Sons/daughters are actively involved in the decisionmaking processes regarding the use of the Internet and other technological assets, as well as are expected to facilitate their parents' supervision. Co-using is described by parents' physical presence when their sons/daughters are using the Internet to facilitate their modeling of digital behaviors and joint participation in the discussion of contents, selection of information and enrollment in online activities. Co-using the Internet foresees sons/daughters' active involvement in the decision-making processes regarding the use of the Internet and technological devices. While co-using the Internet, pupils are expected to understand the risks of the digital era and to play an active role, complementary to the one of their parents, to prevent them.

Parental mediation styles seem to vary for sons/daughters' sex, age, and school level. Parents tend to more frequently employ restrictive mediation with daughters than sons, and with younger than older offspring [26, 27, 28]. Parental mediation has also been associated with parents' educational levels. Higher educational levels seem to be 
related with higher family income, which might facilitate the acquisition of digital devices on the one hand but increase challenges monitoring children's use of the Internet and technological devices on the other hand [27]. Moreover, the restrictive mediation style has been identified as the least effective one preventing offspring's online risk behaviors. Research suggests that the high external control underlying the restrictive parental mediation seems to trigger youths' opposition behaviors and undesirable boomerang effects. On the contrary, active mediation and co-using of the Internet seem to be more effective, as they foster youths' autonomy and preserve responsivity to their needs for support [24]. However, parental mediation is mostly dependent on how parents communicate with their sons/daughters and afford them the possibility to participate in decision-making processes and play an active role attaining an autonomous, self-regulated and responsible use of the Internet and technology [29].

Calls have been made for professionals, among which educational psychologists, to help parents develop competencies to mediate their sons/daughters' use of the Internet and technological devices [26]. A measure to assess parental mediation might be useful to advance knowledge on the topic and to sustain educational psychologists' practices. This study offers preliminary psychometric evidence on the adaptation and validation of the Parental Mediation Scale [24] with Portuguese pre-adolescents.

\section{Method}

\subsection{Participants}

The sample included 328 Portuguese pre-adolescents aged 10 to 13 years old, mostly female $(n=179,54.6 \%)$. At the time of this study, participants were attending middleschool (from $5^{\text {th }}$ to $7^{\text {th }}$ grade). The majority presented no retentions in their academic path $(n=309,94.2 \%)$. As for parents' educational level, the median from mothers was higher $\left(12^{\text {th }}\right.$ grade) than for fathers ( $9^{\text {th }}$ grade).

\subsection{Measures}

Data was collected with a sociodemographic questionnaire and the Parental Mediation Scale (PMS; [24]). The sociodemographic questionnaire was constructed for the purpose of this study. It sought to identify common characteristics among the participants, such as age, gender, school level, history of academic retentions and parents' educational level. Participants were also asked about the approximate number of hours spent on the Internet, and whether they often used it in their free time.

The PMS [24] includes 28 items regarding the rules and practices used by parents to mediate their sons/daughters' use of the Internet. The PMS items [24] were designed to be completed by either parents or sons/daughters and relied on results from previous research on the topic $[25,26,28,30]$. Items are answered in a four-point Likert-type scale $(1=$ never, $4=$ always $)$ and distributed across three dimensions, each corresponding to a parental mediation style (i.e., active mediation, restrictive mediation, and cousing). In a first study employing the measure with Portuguese individuals [31], permission was obtained by the authors of the original PMS version and both instructions and items were translated and adapted to the Portuguese scenery. Based on results from 
exploratory factor analysis, the PMS was reduced to 14 items, enabling the assessment of two dimensions - active/participated mediation and restrictive mediation. The active/participated mediation dimension includes eight items indicative of parents' established rules regarding the content and websites their sons/daughters can search online, and the online activities that sons/daughters can perform along with parents. The restrictive dimension includes six items, according to which parents establish their role analyzing and reviewing their sons/daughters' online messages or e-mail. A Cronbach's alpha value of .82 were obtained for each dimension [31].

\subsection{Procedures}

A non-probability convenience sampling was used. Participants were recruited based on the geographical proximity to the higher education institution hosting this study. Schools from northern Portugal were invited to collaborate and data was collected in the schools that demonstrated interest and availability to support the study. Permissions from the school boards and written consents from parents/legal caregivers and students were obtained. Data was collected in-group at the classroom by a member of the research team, who previously scheduled dates with the school boards and the teachers. The anonymous, confidential and volunteer nature of participation was guaranteed.

Data was analyzed with the Statistical Package for the Social Sciences (IBM SPSS) and the Analysis of Moment Structures (AMOS), versions 26.0 for Windows. Confirmatory Factor Analysis (CFA) was used to evaluate the internal structure of the measure. Two measurement models were tested: a three-dimensional model aligned with the original PMS version [24], considering active mediation, restrictive mediation and co-using as latent factors; a bi-dimensional model aligned with previous results from the Portuguese PMS version [31], considering active/participated mediation and restrictive mediation as latent factors. Minimal requirements for model fit were considered: a nonsignificant $\chi^{2}$-fit statistic; a $\chi^{2}$-fit/df ratio lower than 3; a Comparative Fit Index (CFI) higher than .90; and a Root Mean Squared Error of Approximation (RMSEA) below .06 [32]. Reliability was evaluated with Cronbach's alpha. Descriptive and inferential statistical analyses were computed to explore variations of the PMS scores for groups and associations with other variables.

\section{Results}

Results are organized in two sub-sections. One sub-section presents the internal structure and reliability results of the PMS. It enables the identification of the measurement model that better fits the Portuguese sample's data and reliability. Another subsection presents results on the PMS validity based on differences for groups and relations with other variables. It offers evidence regarding: the variability of parental mediation for girls and boys; the parental mediation's relations with pre-adolescents' age, length of daily use of the Internet, use of the Internet in free time, and parents' school levels. 


\subsection{Internal structure and reliability}

Results from CFA suggested that the three-dimensional model and the bi-factorial model were poorly adjusted to the data. Modification indices were inspected. Based on the correlation of errors of measurement, the modified three-dimensional and bi-dimensional models improved their fit (Table 1). Still, the bi-dimensional model was preferred, as it: presented better fit statistics; suggested that latent variables were correlated but evaluating different aspects of parental mediation; sustained a clear distribution of items/observable variables per latent variables; and presented good internal consistency for both latent variables. In the bi-dimensional model, the correlation between the latent variables was -.44 (Figure 1). A Cronbach's alpha value of .82 was obtained for the active/participated mediation and the restrictive mediation dimensions.

Table 1. Model fit from tested measurement models

\begin{tabular}{lcccc}
\hline \multicolumn{1}{c}{ Internal Structure Model } & $\chi^{2}$ & $\chi^{2} / \mathrm{df}$ & CFI & RMSEA \\
\hline Three-dimensional & $1145.75^{* * *}$ & 5.05 & .90 & .07 \\
Modified three-dimensional & $129.33^{* * *}$ & 1.82 & .96 & .05 \\
Bi-dimensional & $210.99 * * *$ & 2.78 & .90 & .07 \\
Modified bi-dimensional & $123.96^{* * *}$ & 1.70 & .96 & .05 \\
\hline
\end{tabular}
$* * * p<.001$

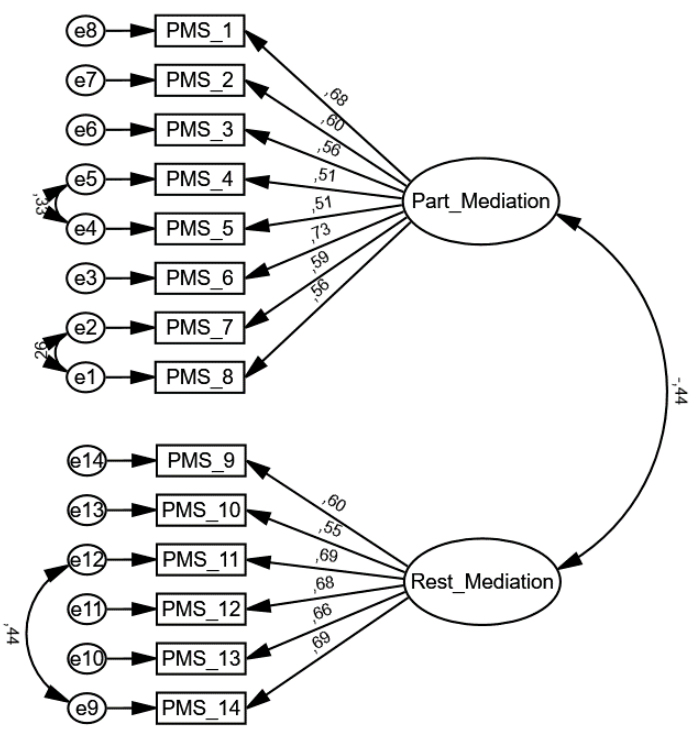

Fig. 1. Factor loadings in the bi-factorial measurement (model of the Portuguese PMS version.

\subsection{Variations for groups and associations with other variables}

Statistically significant differences were found in restrictive mediation for pre-adolescents' sex, $t(326)=2.90, p=.004$. Males perceived their parents as using more restrictive mediation practices than females. Statistically significant correlations among 
participants' age and parental mediation were also identified. Pre-adolescents' age was negatively associated with parental active/participated mediation, $r=-.23, p<.001$, but positively correlated with parental restrictive mediation, $r=.20, p<.001$.

Participants' school levels were positively and statistically significantly associated with parental restrictive mediation, $r_{s}=.21, p<.001$, but negatively associated with parental active/participated mediation, $r_{s}=-.26, p<.001$. Moreover, restrictive parental mediation was positively and statistically significantly correlated with the educational levels from both mothers, $r_{s}=.158, p=.006$, and fathers, $r_{s}=.14, p=.018$.

Participants reported making a daily use of the Internet, with 97 (29.6\%) using it less than one hour per day, 196 (59.8\%) using it from one to three hours, 21 (6.4\%) using it from five to seven hours, and 14 (4.3\%) using it more than seven hours per day. When asked if they got stuck on the Internet when having nothing to do, 67 (20.4\%) participants answered "no", 180 (54.9\%) "sometimes", and 81 (24.7\%) "often". Statistically significant relations between parental mediation and participants' use of the Internet were found. Active/participative mediation was negatively correlated with the length of Internet use per day, $r=-.31, p<.01$, and the frequency in which participants felt they got stuck on the Internet, $r=-22 ., p<.01$. Restrictive mediation was positively correlated with the length of Internet use per day, $r=-.35, p<.01$, and the frequency by which participants felt they got stuck on the Internet, $r=.17 ., p=.002$.

\section{Discussion}

The purpose of this study was to offer preliminary psychometric evidence of the PMS [24] with Portuguese pre-adolescents. Overall, results demonstrated that the Portuguese PMS version enables a valid and reliable measurement of pre-adolescents' perceived parental mediation of their use of the Internet.

Internal structure results suggested that the Portuguese PMS version affords the assessment of parental active/participated mediation and restrictive mediation. These findings are consistent with those derived from a previous study in Portugal employing exploratory factor analyses [31]. However, no support for the original three-dimensional structure of the measure [24] was obtained. Variations in the PMS internal structure for the original and Portuguese versions are illustrative of current discussions regarding the dimensionality of the parental mediation construct. Personal and contextual factors might also need to be considered when investigating this topic. Among personal factors, it would be useful to expand this study with older adolescents in middle-school and high-school, as changes in cognitive and social-emotional development during adolescence might sustain different interpretations of the items. Developmental changes regarding abstract thinking and perspective taking might sustain different views of parental mediation from early-, mid-, and late-adolescence, and perhaps sustain varying fits from bi-factorial and three-factorial measurement models according to age. As for contextual factors, social-cultural aspects of parental mediation need to be taken into consideration. It might be the case that parenting relations and practices are still hierarchically conceived in Portuguese families, whereby pre-adolescents might better differentiate restrictive from active/participated mediation practices than discern between active and co-using practices. Additional cross-regional and cross-cultural studies 
might help identify social-cultural communalities and particularities of parental mediation of their sons/daughters' use of the Internet.

As for variations in the PMS scores for groups and associations with other variables, results suggested that males perceived more restrictive mediation practices from parents than females. These results are contrary to other findings suggesting that restrictive parental mediation is more frequent for females than males [26, 27, 28]. As males seem to mostly use the Internet to access games [10], they might struggle balancing the use of the Internet for academic work and for leisure. Parents might be sensitive to such difficulties and decide to employ restrictive mediation practices to externally prompt such a balance. As for pre-adolescents' age, older students perceived higher parental restrictive mediation than younger peers. These findings are inconsistent with the literature, which suggests that parental restrictive mediation decreases with offspring's age $[26,27,28]$. Still, as pre-adolescence is a fruitful period in terms of developmental changes and peer connectedness, parents may feel the need to employ restrictive practices to protect their offspring from the hazards of the Internet, such as sexting or cyberbullying $[13,15,25]$. Still, future mixed-method research covering parents' concerns, the uses of the Internet made by pre-adolescents and changes throughout the adolescent period of the lifespan might enlighten the understanding of these results.

This study also found that high educational levels from mothers and fathers are related to high restrictive mediation. These results are aligned with extant literature and seem to illustrate the two faces of a single coin - parents holding higher educational levels and income might more easily access Internet services and technological devices but might simultaneously be highly aware of the risks of the Internet and, therefore, employ restrictive practices to protect their offspring [27]. However, our results alerted that parental restrictive mediation seems to be linked with sons/daughters' use of the Internet during longer periods of the day and with sons/daughters increased likelihood of feeling stuck on the Internet. These findings are consistent with the literature that has already identified the restrictive mediation as the least effective style compared to active mediation and co-using [24]. Parental restrictive mediation seems to play a boomerang effect, as its high demandingness and external control might trigger youths' desire to use the Internet, ultimately engaging in online risk behaviors [24].

Future studies might add evidence on the psychometric properties of the PMS in Portugal, by enlarging the age-span, school levels and geographic regions of the samples. Nonetheless, this study might stimulate the use of the PMS in research focused on parents' mediation of their sons/daughters' use of the Internet. For example, research exploring relations among parental mediation, parenting styles, relational and communication practices with their offspring might advance the scientific knowledge on this topic and assert a view of mediating the use of the Internet and technological devices as an important part of parenting in the digital era.

This study might additionally be helpful for educational psychologists' practices. On the one hand, the Portuguese PMS version might serve psychological assessment practices. This measure might be used in a screening of the parental mediation styles that seem to prevail in a specific context (e.g., school), thus sustaining an evaluation of local needs and supporting educational psychologists' decisions about practices to develop with pre-adolescents and parents. On the other hand, the Portuguese PMS version might stimulate educational psychologists' interventions with parents. Psychological consultancy, group sessions and workshops might be prepared by 
educational psychologists to afford parents the possibility to openly discuss concerns regarding parenting in the digital era, share experiences and practices, as well as engage in a role-play of communication and mediation practices. As parents' communication and relational interactions with their sons/daughters are crucial to foster an autonomous, self-regulated and responsible use of the Internet and technological devices [29], parents need to be acknowledged and supported by educational psychologists.

\section{Authors' Note}

This study was supported by the Portuguese Foundation for Science and Technology Centre for Philosophical and Humanistic Studies (UID/FIL/00683/2020).

\section{References}

1. EUROSTAT homepage: https://ec.europa.eu/eurostat/statistics-explained/index.php?title=Digital_economy_and_society_statistics_-_households_and_individuals/pt, last accessd 2020/03/12

2. Martínez de Morentin, J. I., Cortés, A., Medrano, C., Apodaca, P.: Internet use and parental mediation: A cross-cultural study. Computers \& Education, 70, 212-221 (2014). https://doi.org/10.1016/j.compedu.2013.07.036

3. Weitz, P.: Psychotherapy 2.0: Where psychotherapy and technology meet. $2^{\text {nd }}$ ed. Routledge, New York (2018).

4. Chauhan, S.: A meta-analysis of the impact of technology on learning effectiveness on elementary students. Computers \& Education, 105, 14-30. (2017). https://doi.org/10.1016/j.compedu.2016.11.005

5. Eynon, R., Malmberg, L. E.: A typology of young people's Internet use: Implications for education. Computers \& Education, 56(3), 585-595 (2011). https://doi.org/10.1016/j.compedu.2010.09.020

6. Livingstone, S., Haddon, L., Görzig, A., Ólafsson, K.: Risks and safety on the internet: the perspective of European children: full findings and policy implications from the EU Kids Online survey of 9-16 year olds and their parents in 25 countries. EU Kids Online Network, London (2011).

7. EU Kids homepage, http://eprints.lse.ac.uk/33732/, last accessed 2018/12/19.

8. Martínez de Morentin, J. I., Cortés, A., Medrano, C., Apodaca, P.: Internet use and parental mediation: A cross-cultural study. Computers \& Education, 70, 212-221 (2014). https://doi.org/10.1016/j.compedu.2013.07.036

9. Priewasser, B., Roessler, J., Perner, J.: Competition as rational action: Why young children cannot appreciate competitive games? Journal of Experimental Child Psychology, 116, 545559 (2012). https://doi.org/10.1016/j.jecp.2012.10.008.

10. Valcke, M., De Wever, B., Van Keer, H., Schellens, T.: Long-term study of safe Internet use of young children. Computers \& Education, 57(1), 1292-1305 (2011). https://doi.org/10.1016/j.compedu.2011.01.010

11. Brandtzaeg, P., Heim, J., Karahasanovic, A.: Understanding the new digital divide- A typology of internet users in Europe International. Journal of Human Computer Studies, 69(3), 123-138 (2011). https://doi.org/10.1016/j.ijhes.2010.11.004

12. Gonçalves, B. G., Nuernberg, D.: A dependência dos adolescentes ao mundo virtual. Revista de Ciências Humanas 46(1), 165-182 (2012). 
13. Astorga-Aguilar, C., Schmidt-Fonseca, I.: Peligros de las redes sociales: Cómo educar a nuestros hijos e hijas en ciberseguridad. Revista Electrónica Educare, 23(3), 201 (2019). https://doi.org/10.15359/ree.23-3.17

14. Ramírez-García, A., Aguaded-Gómez, I.: E-parenting +" a través de una Escuela de Familias: Formación parental como transferencia desde la investigación. ICONO 14, 18(2), 353377 (2020) https://doi.org/10.7195/ri14.v18i2.1458

15. Livingstone, S., Mascheroni, G., Ólafsson, K., \& Haddon, L., (2014) Children's online risks and opportunities: comparative findings from EU Kids Online and Net Children Go Mobile. London: London School of Economics and Political Science. Homepege www.eukidsonline.net e www.netchildrengomobile.eu, accessed 2018/02/11.

16. Rodríguez-de-Dios, I., Igartua, J. J., Gonzalez-Vazquez, A.: Development and validation of a digital literacy scale for teenagers. In: $4^{\text {th }}$ International Conference on Technological Ecosystems for Enhancing Multiculturality Proceedings, pp. 1067-1072. Association for Computer Machinery, New York, USA (2016). https://doi.org/10.1145/3012430.3012648

17. Rodríguez-de-dios, I., Oosten, J. M. F., Igartua, J. J.: A study of the relationship between parental mediation and adolescents' digital skills, online risks and online opportunities, Computers in Human Behavior, 82, 186-198 (2018). https://doi.org/10.1016/j.chb.2018.01.012.

18. Gabrielli, J., Tanski, S. E.: The A, B, Cs of youth technology access: Promoting effective media parenting, Clinical Pediatrics, 59(4-5), 496-499 (2020). https://doi.org/10.1177/0009922819901008

19. Zaman, B., Nouwen, M., Vannattenhoven, J., Ferrerre, E., Van Looy, J.: A qualitative inquiry into the contextualized parental mediation practices of young children's digital media use at home, Journal of Broadcasting \& Electronic Media, 60(1), 1-22 (2016). http://dx.doi.org/10.1080/08838151.2015.1127240

20. Tabone, S., Messina, L.: Personal uses of internet and perceptions of parental mediation: A research with children 10 and 11 years old, Children, 2, 2077-2082 (2010). https://doi.org/10.1016/j.sbspro.2010.03.284

21. Almeida, A. N., Alves, N. A., Delicado, A: As crianças e a internet em Portugal: Perfís de uso, Sociologia, Problemas e Práticas, 65, 9-30 (2011).

22. Valcke, M., De Wever, B., Van Keer, H., Schellens, T.: Long-term study of safe Internet use of young children, Computers \& Education, 57(1), 1292-1305 (2011). https://doi.org/10.1016/j.compedu.2011.01.010

23. Chiong, C., Shuler, C.: Learning: Is there an app for that? Investigations of young children's usage and learning with mobile devices and apps. The Joan Ganz Cooney Center at Sesame Workshop, New York (2010).

24. Yubero, S., Larranaga, E., Navarro, R., Elche, M.: Parents, children and Internet use: Family socialization on the Internet, Universitas Psychologica, 17(2), 88-100 (2018). https://doi.org/10.11144/javeriana.upsy17-2.phis

25. Mesh, G. S.: Parental mediation, online activities, and cyberbullying, CyberPsychology \& Behavior, 12(4), 387-393 (2009). https://doi.org/10.1089/cpb.2009. 0068

26. Livingstone, S., Helsper, E. J.: Parental mediation and children's internet use, Journal of

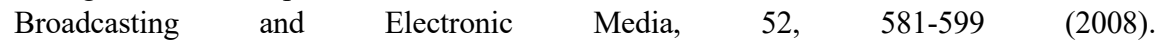
https://doi.org/10.1080/08838150802437396.

27. Özgür, H.: The relationship between internet parenting styles and internet usage of children and adolescents, Computer in Human Behavior, 60, 411-424. https://doi.org/10.1016/j.chb.2016.02.081

28. Livingstone, S., Ólafsoon, K., Helsper, E. J., Lupiáñez-Villanueva, F., Veltri, G., Folkvord, F.: Maximizing opportunities and minimizing risks for children online: The role of digital 
skills in emerging strategies of parental mediation, Journal of Communication, 67(1), 82105 (2017).

29. Fikkers, K. M., Piotrowski, J. T., Valkenburg, P., M.: A matter of style? Exploring the effects of parental mediation styles on early adolescent's media violence exposure and aggression, Journal Computers in Human Behavior, 70, 407-415 (2017). https://doi.org/ 10.1016/j.chb.2017.01.029

30. Lee, S. K., Chae, Y. W.: Children's Internet use in a family context: Influence on family relationships and parental mediation, CyberPsychology \& Behavior 10(5), 640-644 (2007).

31. Dias, P. C., Fernandes, R.: Mediação parental no uso da internet em estudantes dos 10 aos 13 anos [Parental mediation on Internet use in students aged 10 to 13 years]. Paper presented at the VI Iberian Conference on Innovation in Education with Information and Communication Technologies, Azores, Portugal (2020).

32. Kline, R. B.: Principles and practice of structural equation modeling. $4^{\text {th }}$ ed. Guilford Press, New York (2015). 